\title{
Revisando e Aprendendo através da Teleaula
}

Recebido em 29.04.2015. Aprovado em 05.05. 2015 Avaliado pelo sistema double blind review

\section{Érica Cristina dos S. B. Machado}

cemissionariomarioway@gmail.com

Colégio Estadual Missionário Mário Way - Campo Grande - RJ - Brasil

\section{Resumo}

O presente projeto visa a implementação com o uso de tecnologia, a fim de aumentar os resultados da Escola. De forma a fazer com que a aprendizagem e/ou reaprendizagem não esteja restrito ao Espaço Escolar.

Para que o objetivo seja cumprido, vamos oferecer através de um site criado na internet para este fim, tele aulas nas disciplinas de maior dificuldade entre os alunos. Estas aulas serão gravadas pelos próprios professores das disciplinas e catalogadas por assunto e conteúdo abordado.

A divulgação das mesmas será realizada através de panfletos, cartazes, murais e professores, assim como pelos alunos representantes.

Palavras-chaves: Educação. Tecnologias de aprendizagem. Plano de empreendimento. Teleaula.

\section{Caracterização da Escola}

A escola "Colégio Estadual Missionário Mário Way", fundada em 2014 e localizada em Campo Grande, Rio de Janeiro atende a 1588 alunos distribuídos nas seguintes séries: $1^{\circ}, 2^{\circ} 3^{\circ}$ Ano do Ensino Médio e NEJA (Nova Educação de Jovens e Adultos).

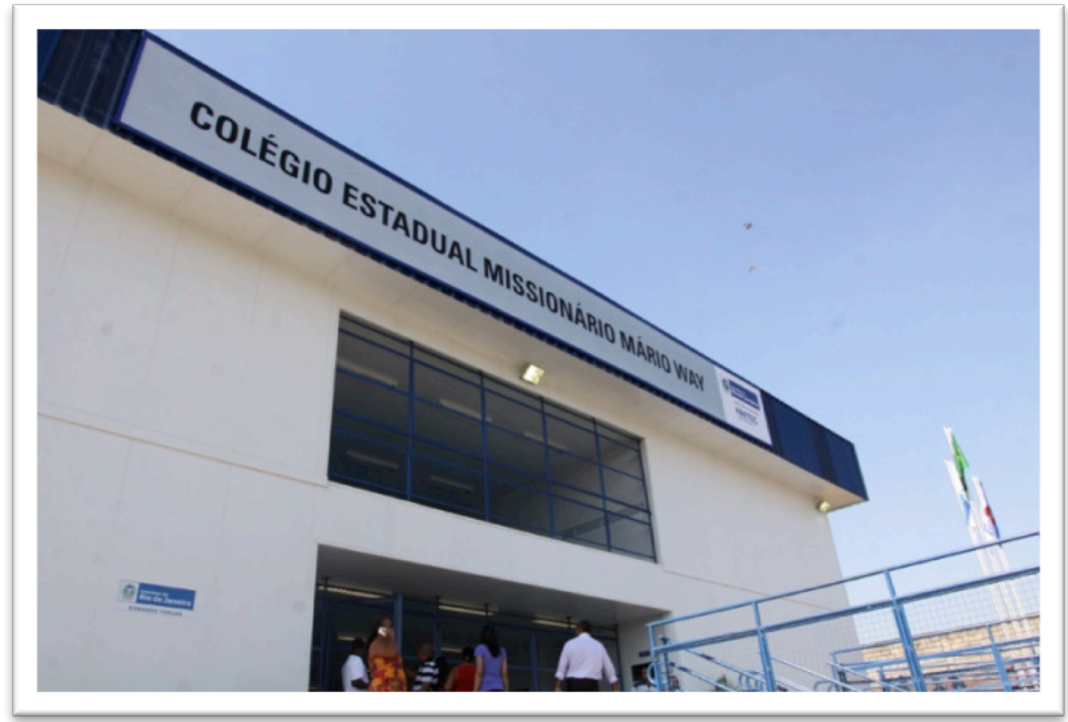




\section{Érica Cristina dos S. B. Machado}

Missão:Preparar nosso aluno para dar continuidade à sua formação acadêmica, o exercício da cidadania, 0 ingresso no mercado de trabalho com igualdade de oportunidades e tomada de consciência ambiental.

\section{Visão:}

Queremos que o Colégio Estadual Missionário Mário Way seja reconhecido como referência de eficiência, eficácia e qualidade de ensino que possibilite os discentes a uma trajetória de sucesso.

\section{Instalações:}

Em 2001 foi fundado o Colégio Estadual Irmã Dulce. Devido a muitos problemas estruturais, nova Unidade foi construída pela FAETEC, contratada pela Secretaria de Educação. A nova unidade passou a se chamar Colégio Estadual Missionário Mário Way.

O CE Missionário Mário Way, por ser uma Unidade construída em 2014 possui ótimas instalações sendo: 18 salas com ar refrigerado, biblioteca, sala de informática, Secretaria, Direção, sala dos professores, Refeitório, Auditório, Laboratório de Artes, Ciências, Matemática e Física, Quadra de Esportes e Vestiários e Estacionamento.

\section{Breve histórico}

O quadro a seguir apresenta a relação dos acontecimentos mais relevantes para a evolução da escola, desde a fundação até hoje.

\begin{tabular}{|c|c|}
\hline Ano & \begin{tabular}{c} 
Acontecimentos relevantes \\
\hline 2001
\end{tabular} \\
\hline 2014 & É Fundado o CE Irmã Dulce \\
\hline 2014 & Março/14 - Designação para que assumisse a Gestão da Unidade Escolar. \\
\hline
\end{tabular}

\section{Professores e funcionários}

A equipe é formada por 55 professores, distribuídos da seguinte forma:

\begin{tabular}{|c|c|}
\hline $\begin{array}{c}\text { Disciplina / Área } \\
\text { Ciências da Natureza Matemática e Suas tecnologias (química, } \\
\text { física e biologia) }\end{array}$ & Quant. de professores \\
\hline $\begin{array}{c}\text { Linguagem códigos e suas tecnologias (português, literatura, artes, } \\
\text { educação física) }\end{array}$ & 20 \\
\hline $\begin{array}{c}\text { Ciências Humanas e suas tecnologias (história, sociologia, geografia } \\
\text { e filosofia) }\end{array}$ & 16 \\
\hline Língua Estrangeira (Inglês e Espanhol) & 06 \\
\hline
\end{tabular}

No total destes professores, apenas 07 estão em regime de Contrato temporário, sendo a grande maioria efetivos da Unidade, alguns poucos ainda apenas complementam sua carga horária de matrícula nesta $U \mathrm{E}$. Dentre o nosso corpo docente apenas $10 \%$ possuem titulação de mestrado ou Doutorado, 40\% possuem especializações em sua área ou na área da Educação.

Além disso, a escola conta com 13 funcionários de apoio, sendo terceirizados: 6 Auxiliares de Serviços Gerais e 5 preparadores de Merenda. Estatutários, temos: 1 Inspetor de alunos e uma Coordenadora de turno. 


\section{Perfil dos alunos}

Com relação a disciplina escolar o grupo pode ser classificado em grau médio, relatando apenas problemas comuns a idade, ou seja não trata-se de uma comunidade agressiva, em geral os discentes atendes bem ao chamado quando por indisciplina. Na organização escolar os alunos estão distribuídos por séries e turnos da seguinte maneira:

\begin{tabular}{|c|c|c|c|c|c|c|c|c|}
\hline \multirow[b]{2}{*}{ Série/Ano } & \multirow{2}{*}{$\begin{array}{l}\text { Média } \\
\text { de } \\
\text { idade }\end{array}$} & \multirow{2}{*}{$\begin{array}{l}\text { Total de } \\
\text { alunos }\end{array}$} & \multicolumn{2}{|c|}{ Manhã } & \multicolumn{2}{|c|}{ Tarde } & \multicolumn{2}{|c|}{ Noite } \\
\hline & & & $\begin{array}{c}\mathrm{N}^{\circ} \\
\text { alunos }\end{array}$ & $\begin{array}{l}\mathrm{N}^{0} \\
\text { turmas }\end{array}$ & $\begin{array}{c}\mathrm{N}^{0} \\
\text { alunos }\end{array}$ & $\begin{array}{c}\mathrm{N}^{0} \\
\text { turmas }\end{array}$ & $\begin{array}{c}\mathrm{N}^{0} \\
\text { alunos }\end{array}$ & $\begin{array}{c}\mathrm{N}^{0} \\
\text { turmas }\end{array}$ \\
\hline $1^{\circ}$ E.M. & 15,9 & 787 & 434 & 12 & 353 & 9 & 0 & 0 \\
\hline $2^{\circ}$ E.M. & 16,8 & 284 & 159 & 4 & 125 & 4 & 0 & 0 \\
\hline $3^{\circ}$ E.M. & 18 & 162 & 104 & 3 & 58 & 2 & 0 & 0 \\
\hline $1^{\circ} \mathrm{EM} .(\mathrm{EJA})$ & $N / A$ & 0 & 0 & 0 & 0 & 0 & 35 & 2 \\
\hline $2^{\circ}$ EM.(EJA) & $N / A$ & 0 & 0 & 0 & 0 & 0 & 71 & 2 \\
\hline $3^{\circ}$ EM.(EJA) & $N / A$ & 0 & 0 & 0 & 0 & 0 & 33 & 1 \\
\hline $4^{\mathrm{a}} \mathrm{EM}(\mathrm{EJA})$ & $N / A$ & 0 & 0 & 0 & 0 & 0 & 61 & 2 \\
\hline TOTAL & - & & & & & & & \\
\hline
\end{tabular}

Os alunos da Unidade em sua maioria residem próximo à Escola, poucos veem de locais mais distantes. Em geral apenas trabalham os alunos do terceiro ano que fazem estágios e atividades remuneradas. Estes alunos participam de atividades escolares com muito afinco e seus responsáveis, salvo algumas exceções respondem as convocações e participam das reuniões.

\section{Características do entorno}

A Unidade Escolar fica muito bem localizada, e frente à Avenida Cesário de Melo, com fácil acesso ao BRT, sistema de transportes muito utilizado pelos alunos. A violência que temos conhecimento está em grande parte regionalizada aos bairros de moradia. Temos na Unidade o acompanhamento do PROEIS (sistema de Policiamento realizado pela parceria da Polícia com a SEEDUC), o que diminui muito o índice de depredação e violência.

\section{Identificação do problema e da oportunidade}

A identificação do problema partirá de um diagnóstico da Unidade Escolar. Para isso, foram observadas as principais avaliações externas, avaliações da equipe pedagógica, bem como relatórios internos de desempenho.

IDEB

\begin{tabular}{|c|c|c|c|c|c|c|c|c|c|c|c|c|c|}
\hline & \multicolumn{5}{|c|}{ Ideb Observado } & \multicolumn{8}{|c|}{ Metas Projetadas } \\
\hline Estado $*$ & $2005 *$ & $2007 *$ & $2009 *$ & $2011^{*}$ & $2013^{*}$ & $2007^{*}$ & $2009 *$ & $2011^{*}$ & $2013^{*}$ & $2015^{*}$ & $2017 *$ & $2019 *$ & $2021 *$ \\
\hline Rio de Janeiro & 2.8 & 2.8 & 2.8 & 3.2 & 3.6 & 2.8 & 2.9 & 3.1 & 3.3 & 3.7 & 4.1 & 4.4 & 4.6 \\
\hline
\end{tabular}

O IDEB é feito por amostragem, portanto não temos o resultado específico da Escola, pois não participamos da Avaliação. 
Avaliação Estadual (Rio de Janeiro)

\section{CE MISSIONÁRIO MÁRIO WAY}

Ano: 2014

ENSINO MÉDIO

METAS BIMESTRAIS DO IDERJ

\begin{tabular}{|c|c|c|c|}
\hline $1^{\circ}$ BIMESTRE & $2^{\circ}$ BIMESTRE & $3^{\circ}$ BIMESTRE & META 2014 \\
\hline 2,2 & 2,5 & 2,8 & 3,1 \\
\hline
\end{tabular}

ID E IF

\begin{tabular}{|c|c|c|c|c|}
\hline ID & 3,4 & 3,7 & 3,9 & 4,1 \\
\hline IF & 0,63 & 0,67 & 0,71 & 0,75 \\
\hline
\end{tabular}

META ID $=4,1 \quad$ META IF $=0$,75

RESULTADOS $1^{\circ}, 2^{\circ}$ BIMESTRES - 2014

\begin{tabular}{|c|c|c|c|c|c|}
\hline ID & IF & IDERJ & META IDERJ & DESVIO & FAROL \\
\hline 3,1 & 0,54 & 1,70 & 2,2 & $-22 \%$ & \\
\hline 3,1 & 0,49 & 1,50 & 2,5 & $-40 \%$ & \\
\hline & & & 2,8 & & \\
\hline
\end{tabular}

- $\quad$ Ressaltamos que a sinalização: cor vermelha significa que as metas propostas não foram alcançadas no tempo previsto e que é preciso atenção a este fato. Por isso a simbolização: Farol Vermelho.

Metas bimestrais do IDERJ (ID)

\begin{tabular}{|l|c|c|c|c|}
\multicolumn{2}{c}{$1^{\circ} \mathrm{BIM}$} & \multicolumn{2}{c}{ 2 $^{\circ} \mathrm{BIM}$} & \multicolumn{2}{l}{$4^{\circ} \mathrm{BIM}$} \\
\hline NEJA & 1,8 & 2,1 & 2,3 & 2,6 \\
\hline
\end{tabular}

Um dos principais problemas identificados são o desinteresse e desmotivação dos alunos. Em enquete informal professores demonstram este fator como principal defasagem nas avaliações internas e internas. $A$ meta proposta não tem sido alcançada devido à desvalorização atribuída pelos educandos às avaliações, principalmente as externas.

\section{Principais problemas identificados}

Conforme já mencionado anteriormente o desinteresse e a desmotivação do corpo discente é apontado pelos docentes como principal fator que interfere na aprendizagem.

Seguido deste fato apontamos professores desinteressados que acabam por corroborar com a defasagem de aprendizagem, pois uma vez desmotivados esses professores não planejam atividades interessantes que 
despertem o interesse dos alunos na aprendizagem.

A Unidade Escolar como um todo não consegue atingir as metas propostas pela SEEDUC para alcançar os objetivos visando à participação e aprendizagem dos alunos. 0 corpo discente como um todo não valoriza a realização das avaliações, acreditamos que este seja um ponto a ser considerado no desenvolvimento desta atividade.

A clientela não valoriza os conteúdos das aulas, não se sabe se por falta de entendimento e/ou interesse, de modo que também não alcança um bom desempenho nas avaliações sejam elas internas ou externas.

\begin{tabular}{|c|c|c|c|c|c|}
\hline Problemas & G & U & T & GxUxT & Prioridade \\
\hline $\begin{array}{c}\text { Baixo desempenho dos alunos nas disciplinas: } \\
\text { Matemática, química, física e Sociologia e Filosofia }\end{array}$ & 5 & 5 & 4 & 100 & $1^{0}$ \\
\hline Não alcance das Metas Propostas & 5 & 3 & 1 & 15 & $2^{0}$ \\
\hline Desmotivação do corpo discente & 5 & 4 & 4 & 80 & $3^{\circ}$ \\
\hline Desinteresse do corpo docente & 2 & 2 & 2 & 8 & $4^{0}$ \\
\hline $\begin{array}{c}\text { Desvalorização na realização das Avaliações } \\
\text { internas e externas }\end{array}$ & 4 & 3 & 2 & 24 & $5^{0}$ \\
\hline
\end{tabular}

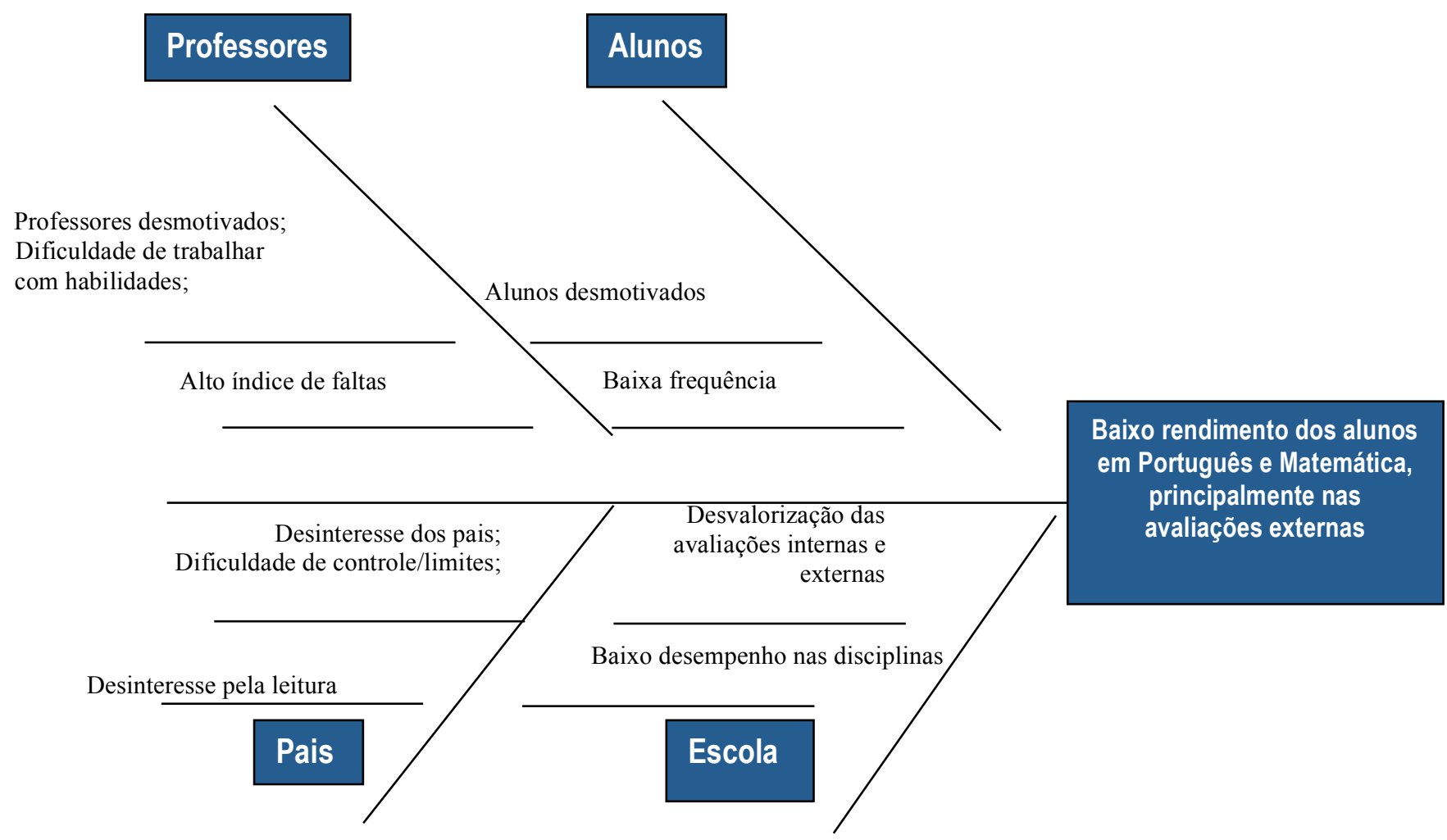




\section{Érica Cristina dos S. B. Machado}

\section{Análise SWOT}

\begin{tabular}{|c|c|c|}
\hline & Aspectos favoráveis & Aspectos desfavoráveis \\
\hline & FORÇAS & FRAQUEZAS \\
\hline $\begin{array}{l}\text { 형 } \\
\text { 웧 } \\
\text { 영 }\end{array}$ & $\begin{array}{l}\text {-Adequação série/idade } \\
\text {-Prevenção ao uso de drogas } \\
\text {-Aceitação das diferenças } \\
\text {-Uso responsável das verbas públicas }\end{array}$ & $\begin{array}{l}\text {-Baixo índice de aprovação sem dependência } \\
\text { - Não alcance das metas propostas } \\
\text {-Não recuperação dos alunos } \\
\text {-Desvalorização na realização das atividades } \\
\text { internas e externas }\end{array}$ \\
\hline & OPORTUNIDADES & AMEAÇAS \\
\hline 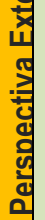 & $\begin{array}{l}\text {-Universidades próximas } \\
\text {-Cursos profissionalizantes livres } \\
\text {-Proximidade de pólo industrial }\end{array}$ & -Uso de drogas lícitas e ilícitas \\
\hline
\end{tabular}

\section{Ações corretivas}

Visando preparar a organização para o desenvolvimento do projeto, no intuito combater as fraquezas e reduzir os possíveis impactos das ameaças, foram definidas as seguintes ações:

1. Motivação e estímulo do interesse dos alunos, buscando reduzir os atrasos e faltas;

2. Revisão dos pré-requisitos básicos para o aluno no início do curso, utilizando as teleaulas, gravadas pelos próprios professores;

3. Oferta de formação continuada aos docentes.

4. Instalação de multimídia em salas de aula.

5. Recuperação com professores auxiliares.

6. Acompanhamento das aulas pela coordenação;

7. Programa "Drogas é uma Droga".

\section{Etapa 1 - Instalação de aparelhos multimídia e telas de projeção.}

Objetivo: Proporcionar um ambiente direcionado para a gravação e reprodução das teleaulas Impacto na aprendizagem: Recursos disponíveis para acesso dos alunos e professores para atividades direcionados as teleaulas

\section{Atividades a serem realizadas:}

\section{Atividade 1.1}

Descrição: Orçamentos para aquisição e instalação de aparelhos multimídia e telas de projeção. 
Duração: 3 meses

Recursos necessários: Aquisição de Projetor e Telas para exibição, colocação dos mesmos nas salas selecionadas.

Equipe envolvida:. Direção e funcionário da manutenção para colocação da aparelhagem;

\section{Atividade 1.2}

Descrição: Teste dos equipamentos a fim de que estejam em pleno funcionamento

\section{Duração: 7 dias}

Recursos necessários: Pagamento do funcionário da manutenção

Equipe envolvida: Técnicos de colocação e informática

\section{Atividade 1.3}

Descrição: Reunião da equipe para programar os conteúdos a serem gravados

Duração: 3 meses

Recursos necessários: Ambiente propício para a atividade e lanche para os envolvidos Equipe envolvida: Professores e equipe pedagógica

\section{Etapa 2 - Capacitação}

Objetivo: Capacitar o corpo docente incentivando o uso de tecnologia moderna, na busca de aulas mais atrativas e motivadoras

Impacto na aprendizagem: .Alunos motivados e aulas interativas, linguagem clara e objetiva visando a aprendizagem

Atividades a serem realizadas:

* - Reunião de conscientização e capacitação do corpo docente;

* - Apresentação do conteúdo aos professores envolvidos

* - Exibição das teleaulas e do site da Escola

\section{Atividade 2.1}

Descrição: Orçamentos de profissional(is) habilitado(s) para proporcionar a capacitação do corpo docente com novas metodologias e uso dos aparelhos multimídia.

Duração: 30 dias

Recursos necessários: Profissional da área tecnológica

Equipe envolvida: Direção, Equipe pedagógica e professores

Etapa 3 - Manutenção

Objetivo: manutenção preventiva da aparelhagem multimídia em sala de aula.

Impacto na aprendizagem: Professores capacitados a operarem os recursos a fim de que a aprendizagem seja significativa

Atividades a serem realizadas:

Atividade 3.1

Descrição: manutenção da aparelhagem multimídia e complementos.

Duração: 30 dias 
Recursos necessários: telesalas em funcionamento.

Equipe envolvida:. Técnico e professores para controle e operação do material

Detalhamento do Produto/Serviço e/ou Processo

Foco do projeto:

Melhoria de Resultados nas disciplinas consideradas críticas Série ou conjunto de séries beneficiadas: alunos do $1^{\circ}, 2^{\circ}$ e $3^{\circ}$ ano do Ensino Médio.

Disciplina ou conjunto de disciplinas trabalhadas:

Matemática, Química, Física, Sociologia e Filosofia.

\section{Etapas do projeto}

$O$ projeto será composto pelas seguintes etapas:

\section{Etapa 1 - Trabalhando a confecção dos conteúdos a serem abordados}

Objetivo: Melhoria nos resultados

Impacto na aprendizagem: Revisão e Aprendizagem dos conteúdos abordados que apresentaram maiores dificuldades nas disciplinas em questão.

Atividades a serem realizadas: Reunião com professores, alunos e Comunidade Escolar para: Apresentação do Programa.

\section{Atividade 1.1}

Descrição: Recrutamento e seleção dos professores que irão gravar as aulas, com os respectivos conteúdos abordados pelo currículo mínimo.

Duração: 60 dias

Recursos necessários: Formulários de apresentação das atividades e filmadora;

Equipe envolvida: Professores e técnico para gravação dos vídeos, criação do site e edição dos mesmos.

\section{Atividade 1.2}

Descrição: Divulgação do site e incentivo dos alunos a utilizarem a ferramenta de aprendizagem.

Duração: 30 dias

Recursos necessários: Folders, murais, dentre outros;

Equipe envolvida: Professores e Funcionários da U E.

\section{Etapa 2 - Utilização e Monitoramento da Ferramenta}

Objetivo: Melhoria nos resultados

Impacto na aprendizagem: Avanços nas disciplinas principalmente nos conteúdos considerados mais críticos e difíceis.

Atividades a serem realizadas: Utilização constante do laboratório de informática a fim de a Comunidade Escolar aprenda a utilizar a ferramenta.

\section{Atividade 2.1}

Descrição: Monitoramento da utilização da Ferramenta no site e principais dúvidas e melhorias.

Duração: 120 dias 
Recursos necessários: Acesso e controle no site, relatórios com estatísticas;

Equipe envolvida: Técnico responsável pelo monitoramento, professores envolvidos no Projeto.

\section{Atividade 2.2}

Descrição: Divulgação e avaliação dos resultados obtidos

Duração: 120 dias

Recursos necessários: Site da interne, e-mail dos professores; murais da Unidade Escolar.

Equipe envolvida: Professores, alunos e comunidade Escolar.

\section{Casos de sucesso}

Nome do Projeto: Telecurso 2000

Nome da organização: Parceria entre a Federação das Indústrias do Estado de São Paulo (FIESP) e a Fundação Roberto Marinho.

Local: $O$ acesso ao Telecurso é garantido por meio da recepção livre pela TV Globo, Canal Futura, TV Educativa, TV Cultura, Rede Minas, Rede Vida e Globo Internacional e em circuito fechado e redes setoriais. Sua programação está presente em $89 \%$ dos lares brasileiros e pelo menos 7 milhões de pessoas assistem a ele semanalmente.

Período em que foi realizado: Lançado em 1995, mas funciona até hoje.

Breve relato do contexto anterior ao projeto: 0 Telecurso 2000 foi lançado quando o país tinha aproximadamente 150 milhões de habitantes, dos quais 66 milhões eram maiores de 15 anos com escolaridade inferior à $5^{\mathrm{a}}$ série do ensino fundamental. Nesse contexto, e cientes de suas responsabilidades sociais, a FIESP, contando com sua experiência educacional de mais de 50 anos do SESI e do SENAI, e a Fundação Roberto Marinho, com notória competência na produção de telecursos, uniram-se para ajudar a reverter esse quadro. Desde 1995, Telecurso vem sendo reconhecido mundialmente como uma metodologia que promove um salto de qualidade na educação, tendo beneficiado mais de 5 milhões de pessoas nas 27.714 tele-salas implantadas em todo o Brasil.

Principais atividades desenvolvidas: 0 Telecurso trabalha com o currículo essencial, complementado por temas transversais, como sexualidade e saúde, segurança alimentar, empreendedorismo, entre outros. Incorporou, também, novos módulos como educação para o trabalho, para a cidadania, defesa do patrimônio e dos bens naturais, além das habilidades básicas necessárias para o bom desempenho profissional e como cidadão.

Resumo dos principais resultados alcançados:

Fonte:http://www.frm.org.br/main.jsp?lumPageld=FF8081811D6C7E31011D923D438A695E\&lumS=projeto\&l umltemld=FF80808122913F1A01229A6BFF873426\&tagld=2815C7F847E348A4A3EE5AA9BC46C232 acesso em 26/09/2014 às 20:37min

Nome do Projeto: Educopédia

Nome da organização: Secretaria Municipal de Educação do Rio de Janeiro

Local: A Educopédia é uma plataforma online colaborativa de aulas digitais

Período em que foi realizado: A $1^{\text {a }}$ fase de testes aconteceu no $2^{\circ}$ semestre de 2010 o Projeto existe atualmente.

Breve relato do contexto anterior ao projeto: Professores em breves relatos informam que anteriormente ao projeto era preciso pesquisar atividades a fim de enriquecer suas aulas, a ferramenta propicia com que 0 aluno estudasse não apenas com o auxílio do professor os conteúdos, mas também sozinhos quando tinham dificuldades ou queriam saber mais sobre algum assunto. 
Principais atividades desenvolvidas: A Educopédia é uma plataforma online colaborativa de aulas digitais, onde alunos e professores podem acessar atividades autoexplicativas de forma lúdica e prática, de qualquer lugar e a qualquer hora. As aulas incluem planos de aula e apresentações voltados para professores que queiram utilizar as atividades nas salas, com os alunos. Cada uma delas possui temas, competências e habilidades contempladas nas orientações curriculares da Secretaria Municipal de Educação do Rio de Janeiro. Essas orientações curriculares de cada ano e cada disciplina foram divididas em 32 aulas digitais, que correspondem às semanas do ano letivo, retiradas àquelas voltadas para avaliações e revisões.

\section{Resumo dos principais resultados alcançados:}

A Educopédia é clara, direta e extremamente intuitiva para que alunos e professores possam utilizá-la sem a necessidade de treinamento. A navegação foi pensada para pessoas com qualquer nível de letramento digital. Além de uma opção prática para professores que desejam integrar novas tecnologias a seu dia-a-dia, a Educopédia passa a ser mais uma alternativa para alunos que perderam aulas; que não compreenderam 0 conteúdo; que precisam de um reforço escolar e também para o desenvolvimento constante e aprofundado de competências e habilidades

Fonte: http://www.educopedia.com.br/SobreEducopedia.aspx-acesso em 26/09/2014 às 21:15min 


\section{Novidade trazida pelo projeto}

Este Projeto tem por diferencial o fato de as teleaulas serem gravadas pelos professores da Unidade Escolar, ou seja, o professor é conhecido pelo aluno que por afinidade ou indicação pode vir a assistir a aula de um outro professor da mesma disciplina e compreender com mais facilidade o conteúdo abordado.

0 aluno poderá também além de tirar dúvidas assistindo as aulas, rever conteúdos passados, assim como conteúdos vindouros nas aulas. 0 que pode vir a ajudá-lo não apenas no que se refere ao aprendizado momentâneo, mas com relação a novos horizontes que por ventura este venha a buscar.

\section{Cronograma de execução}

\begin{tabular}{|c|c|c|c|c|c|c|c|c|c|c|c|c|c|}
\hline \multirow{2}{*}{\multicolumn{2}{|c|}{ Atividades }} & \multicolumn{4}{|c|}{ Ano 1} & \multicolumn{4}{|c|}{ Ano 2} & \multicolumn{4}{|c|}{ Ano 3} \\
\hline & & \multirow{2}{*}{$\begin{array}{l}\text { Jan- } \\
\text { Mar }\end{array}$} & \multirow{2}{*}{$\begin{array}{l}\text { Abr- } \\
\text { Jun }\end{array}$} & \multirow{2}{*}{$\begin{array}{l}\text { Jul- } \\
\text { Set }\end{array}$} & $\begin{array}{l}\text { Out- } \\
\text { Dez }\end{array}$ & $\begin{array}{l}\text { Jan- } \\
\text { Mar }\end{array}$ & $\begin{array}{l}\text { Abr- } \\
\text { Jun }\end{array}$ & $\begin{array}{l}\text { Jul- } \\
\text { Set }\end{array}$ & $\begin{array}{l}\text { Out- } \\
\text { Dez }\end{array}$ & $\begin{array}{l}\text { Jan- } \\
\text { Mar }\end{array}$ & $\begin{array}{l}\text { Abr- } \\
\text { Jun }\end{array}$ & $\begin{array}{l}\text { Jul- } \\
\text { Set }\end{array}$ & $\begin{array}{l}\text { Out- } \\
\text { Dez }\end{array}$ \\
\hline \multirow{2}{*}{ Etapa 1} & Ativ. 1.1 & & & & & & & & & & & & \\
\hline & Ativ. 1.2 & & & & & & & & & & & & \\
\hline \multirow{2}{*}{ Etapa 2} & Ativ. 2.1 & & & & & & & & & & & & \\
\hline & Ativ. 2.2 & & & & & & & & & & & & \\
\hline
\end{tabular}

\section{Gestão Estratégica}

\section{Objetivos estratégicos}

\begin{tabular}{|c|c|c|c|}
\hline Objetivos & Metas & Indicadores & Acompanhamento \\
\hline \multirow{3}{*}{$\begin{array}{l}\text { Aumentar o } \\
\text { Desempenho dos } \\
\text { alunos nas } \\
\text { disciplinas da área } \\
\text { de Exatas: } \\
\text { Química e Física }\end{array}$} & $\begin{array}{c}\text { Aumentar o número de } \\
\text { aprovações nas respectivas } \\
\text { disciplinas em } 5 \% \text { ao final do } \\
\text { primeiro ano de projeto; } 10 \% \text { no } \\
\text { segundo ano e } 15 \% \text { no terceiro. }\end{array}$ & $\begin{array}{l}\text { Avaliações das } \\
\text { disciplinas e } \\
\text { acompanhamento } \\
\text { das avaliações } \\
\text { externas. }\end{array}$ & $\begin{array}{l}\text { Controle bimestral do rendimento das } \\
\text { turmas e definição de ações } \\
\text { corretivas para o planejamento (caso } \\
\text { seja necessário), levando em } \\
\text { consideração também o feedback de } \\
\text { alunos e professores. }\end{array}$ \\
\hline & $\begin{array}{c}\text { Alcançar a meta estabelecida na } \\
\text { avaliação externa } 2,6\end{array}$ & $\begin{array}{c}\text { Resultado da } \\
\text { avaliação externa } 3,2 \\
\text { para o ano de } 2017 .\end{array}$ & $\begin{array}{l}\text { Análise bimestral de habilidades } \\
\text { necessárias. Discussão e } \\
\text { estabelecimento de ações } \\
\text { específicas com base nas avaliações } \\
\text { internas da Unidade. }\end{array}$ \\
\hline & $\begin{array}{l}\text { Aumentar o número de acesso as } \\
\text { teleaulas na plataforma em } 5 \% \\
\text { no final do primeiro ano; } 10 \% \text { no } \\
\text { final do segundo ano e } 15 \% \text { no } \\
\text { final do terceiro ano. }\end{array}$ & $\begin{array}{l}\text { Contadores do site } \\
\text { do Programa e } \\
\text { Pesquisa on line } \\
\text { sobre as aulas } \\
\text { apresentadas. }\end{array}$ & $\begin{array}{l}\text { Monitoramento mensal dos acessos e } \\
\text { download das aulas. }\end{array}$ \\
\hline $\begin{array}{c}\text { Aumentar o } \\
\text { Desempenho dos }\end{array}$ & $\begin{array}{c}\text { Aumentar o número de } \\
\text { aprovações nas respectivas }\end{array}$ & $\begin{array}{l}\text { Avaliações das } \\
\text { disciplinas e }\end{array}$ & $\begin{array}{l}\text { Controle bimestral do rendimento das } \\
\text { turmas e definiçãao de ações }\end{array}$ \\
\hline
\end{tabular}




\begin{tabular}{|c|c|c|c|}
\hline \multirow[t]{2}{*}{$\begin{array}{l}\text { alunos nas } \\
\text { disciplinas da área } \\
\text { de humanas: } \\
\text { Sociologia e } \\
\text { Filosofia }\end{array}$} & $\begin{array}{l}\text { disciplinas em } 5 \% \text { ao final do } \\
\text { primeiro ano de projeto; } 10 \% \text { no } \\
\text { segundo ano e } 15 \% \text { no terceiro. }\end{array}$ & $\begin{array}{l}\text { acompanhamento } \\
\text { das avaliações } \\
\text { externas. }\end{array}$ & $\begin{array}{l}\text { corretivas para o planejamento (caso } \\
\text { seja necessário), levando em } \\
\text { consideração também o feedback de } \\
\text { alunos e professores. }\end{array}$ \\
\hline & $\begin{array}{c}\text { Alcançar a meta estabelecida na } \\
\text { avaliação externa } 2,6\end{array}$ & $\begin{array}{c}\text { Resultado da } \\
\text { avaliação externa } 3,2 \\
\text { para o ano de } 2017 \text {. }\end{array}$ & $\begin{array}{l}\text { Análise bimestral de habilidades } \\
\text { necessárias. Discussão e } \\
\text { estabelecimento de ações } \\
\text { específicas com base nas avaliações } \\
\text { internas da Unidade. }\end{array}$ \\
\hline $\begin{array}{l}\text { Incentivar o } \\
\text { discente para a } \\
\text { realização de } \\
\text { avaliações } \\
\text { internas e externas }\end{array}$ & $\begin{array}{l}\text { Melhorar o rendimento e a } \\
\text { participação dos discentes nas } \\
\text { avaliações externas, aumentando } \\
\text { a participação em } 10 \% \text { no } \\
\text { primeiro ano, } 15 \% \text { no segundo e } \\
20 \% \text { no terceiro ano. }\end{array}$ & $\begin{array}{l}\text { Resultado das } \\
\text { avaliações externas, } \\
\text { principalmente o } \\
\text { índice de participação } \\
\text { da Comunidade } \\
\text { Escolar. }\end{array}$ & $\begin{array}{c}\text { Controle bimestral da participação } \\
\text { dos alunos nas avaliações externas e } \\
\text { monitoramento do alcance das metas } \\
\text { estabelecidas pela SEEDUC. }\end{array}$ \\
\hline
\end{tabular}

\section{Continuidade do projeto}

A continuidade do Projeto se dará com base nos resultados obtidos. As aulas serão continuamente revisadas e as sugestões apresentadas por colegas da área, assim como pelos próprios usuários serão consideradas na hora da revisão e monitoramento dos resultados.

A partir desta revisão e reelaboração dos pontos críticos é possível fazer a manutenção das atividades com o objetivo de que os resultados se mantenham e aumentem de forma gradativa.

\section{Marketing e Comunicação}

\section{Lançamento do projeto}

O Lançamento do Projeto será feito em um coquetel de apresentação para a Comunidade Escolar e convidados. Como estratégia para atrair o público utilizaremos convites individuais e de grupos.

0 auditório será o espaço escolhido para a realização do Evento, será servido também um coquetel para recepcionar os convidados que terão a a oportunidade de assistir a recortes das teleaulas e conversar com a equipe envolvida.

\section{Canais de comunicação e acompanhamento do projeto}

\section{Marketing interno}

O marketing interno será realizado através de e-mails, convites e Banners do Projeto, assim como a página da Escola será periodicamente atualizada com novidades e informações sobre o Projeto.

\section{Marketing externo}

Para o marketing externo será realizado mala direta e e-mail. Informando onde encontrar as teleaulas.

\section{Parceiros estratégicos}

Mediador Tecnológico da Secretaria de Estado de Educação

- O Parceiro contribuirá com a capacitação e auxílio dos professores na utilização das ferramentas propostas;

- Contrapartida da escola: A Escola em contrapartida será loco para realização da atividade com vistas a SEEDUC

- Obtenção da parceria: Para adesão do parceiro será realizado convite a solicitada autorização da SEEDUC.. 


\section{Divulgação de resultados}

A divulgação dos resultados será realizada através de reuniões semestrais a fim de informar a todos os envolvidos o impacto que a utilização das teleaulas tem ocasionado na aprendizagem dos alunos. Sempre será feito um link entre o período anterior e atual com foco nas notas e desenvolvimento dos educandos.

Será incentivado também depoimentos de professores e alunos demonstrando o ganho obtido com o uso do recurso apresentado.

\section{Equipe do projeto}

\section{Equipe interna}

\begin{tabular}{|c|c|c|c|c|}
\hline Cargo & Formação & $\begin{array}{c}\text { Tempo na } \\
\text { escola }\end{array}$ & Experiência anterior & $\begin{array}{c}\text { Responsável } \\
\text { pelas } \\
\text { atividades: }\end{array}$ \\
\hline Diretora & $\begin{array}{c}\text { Graduação/Pós } \\
\text { graduação }\end{array}$ & 1 ano & 18 anos & $\begin{array}{c}\text { Gerenciamento } \\
\text { das Atividades }\end{array}$ \\
\hline $\begin{array}{c}\text { Coordenador } \\
\text { Pedagógico }\end{array}$ & Graduação & 5 anos & 20 anos & $\begin{array}{c}\text { Envolvimento e } \\
\text { auxílio aos } \\
\text { professores }\end{array}$ \\
\hline Professor & Graduação/Licenciatura & 8 anos & 20 anos & $\begin{array}{c}\text { Gravação das } \\
\text { imagens de } \\
\text { teleaulas }\end{array}$ \\
\hline Professor & Graduação/Licenciatura & 6 anos & 10 anos & $\begin{array}{c}\text { Gravação das } \\
\text { teleaulas de } \\
\text { matemática }\end{array}$ \\
\hline Professor & Graduação/Mestrado & 5 anos & 8 anos & $\begin{array}{c}\text { Gravação das } \\
\text { teleaulas de } \\
\text { Física }\end{array}$ \\
\hline Professor & Graduação/Licenciatura & 3 anos & 2 anos & $\begin{array}{c}\text { Gravação das } \\
\text { teleaulas de } \\
\text { Filosofia }\end{array}$ \\
\hline & Graduação/Licenciatura & 3 anos & 3 anos & $\begin{array}{c}\text { Gravação das } \\
\text { telaulas de } \\
\text { sociologia }\end{array}$ \\
\hline
\end{tabular}

\section{Profissionais externos}

\begin{tabular}{|c|c|c|}
\hline Tipo de profissional & Competências necessárias & Participação no projeto \\
\hline Técnico em manutenção & $\begin{array}{l}\text { Habilidades de colocação da } \\
\text { aparelhagem e montagem das } \\
\text { telesalas }\end{array}$ & Trabalho in campo \\
\hline Mediador tecnológico & Conhecimentos de informática & Capacitação dos professores \\
\hline Técnico em informática & Web designer & $\begin{array}{l}\text { Montagem e manutenção do } \\
\text { site da Escola }\end{array}$ \\
\hline
\end{tabular}




\section{Érica Cristina dos S. B. Machado}

\section{Plano Financeiro}

\section{Investimentos (despesas de capital)}

\begin{tabular}{|c|c|c|c|}
\hline Obras e infraestrutura & Ano 1 & Ano 2 & Ano 3 \\
\hline obras & $1.500,00$ & $500,00,00$ \\
\hline Instalações & & & 500,00 \\
\hline Total & $1.000,00$ & 500,00 & 1000,00 \\
\hline
\end{tabular}

\begin{tabular}{|c|c|c|c|}
\hline Material permanente & Ano 1 & Ano 2 & Ano 3 \\
\hline Equipamentos & $8.000,00$ & $4.000,00$ & 5.000 \\
\hline Computadores & $8.000,00$ & $5.000,00$ & $\mathbf{9 . 0 0 0 , 0 0}$ \\
\hline
\end{tabular}

\section{Despesas correntes}

\begin{tabular}{|l|c|c|c|}
\hline \multicolumn{1}{|c|}{ Material de consumo } & Ano 1 & Ano 2 & Ano 3 \\
\hline Resmas de papel A4 & 1200,00 & 1200,00 & 1348,32 \\
\hline Tintas impressora & 1440,00 & 1440,00 & 539,32 \\
\hline manutenção do site & 480,00 & 480,00 & 1348,32 \\
\hline material de escritório & 1200,00 & 1200,00 & 1348,32 \\
\hline envio de mala direta & 1200,00 & 1200,00 & 1348,32 \\
\hline Resmas de papel A4 & 1200,00 & 1200,00 & $6.720,00$ \\
\hline
\end{tabular}




\begin{tabular}{|c|c|c|c|}
\hline Gastos com locomoção & Ano 1 & Ano 2 & Ano 3 \\
\hline Passagens e Locomoção & $2.400,00$ & $2.400,00$ & $2.400,00$ \\
\hline Total & $2.400,00$ & $2.400,00$ & $2.400,00$ \\
\hline
\end{tabular}

\begin{tabular}{|c|c|c|c|}
\hline \multicolumn{1}{|c|}{ Serviços de terceiros } & Ano 1 & Ano 2 & Ano 3 \\
\hline Técnico de informática & $4.800,00$ & $4.800,00$ & $4.800,00$ \\
\hline Mediador tecnológico & & & $4.800,00$ \\
\hline Funcionário da manutenção & $3.600,00$ & $3.600,00$ & $3.600,00$ \\
\hline Total & & & $13.200,00$ \\
\hline
\end{tabular}

\section{Recursos do edital}

\begin{tabular}{|c|c|c|c|c|}
\hline Tipo de item & Ano 1 & Ano 2 & Ano 3 & Total \\
\hline Despesas de Capital & $\mathbf{1 8 . 5 0 0 , 0 0}$ & $\mathbf{1 0 . 0 0 0 , 0 0}$ & $\mathbf{1 0 . 0 0 0 , 0 0}$ & $\mathbf{3 8 . 5 0 0 , 0 0}$ \\
\hline Obras e infraestrutura & $2.500,00$ & $1.000,00$ & $1.000,00$ & $4.500,00$ \\
\hline Material permanente & $16.000,00$ & $9.000,00$ & $9.000,00$ & $34.000,00$ \\
\hline Despesas Correntes & $\mathbf{2 2 . 3 2 0 , 0 0}$ & $\mathbf{2 2 . 3 2 0 , 0 0}$ & $\mathbf{2 2 . 3 2 0 , 0 0}$ & $\mathbf{6 6 . 9 6 0 , 0 0}$ \\
\hline Material de consumo & $6.720,00$ & $6.720,00$ & $6.720,00$ & $20.160,00$ \\
\hline Gastos com locomoção & $2.400,00$ & $2.400,00$ & $2.400,00$ & $7.200,00$ \\
\hline Serviços de terceiros & $13.200,00$ & $13.200,00$ & $13.200,00$ & $39.600,00$ \\
\hline Total do projeto & $40.820,00$ & $32.320,00$ & $32.320,00$ & $105.460,00$ \\
\hline
\end{tabular}

\section{Contrapartida}

\begin{tabular}{|l|c|c|c|c|c|}
\hline \multicolumn{1}{|c|}{ Profissionais } & $\begin{array}{c}\text { Horas dedicadas } \\
\text { ao projeto }\end{array}$ & Valor médio/hora & \multicolumn{2}{|c|}{ Contrapartida por profissional } \\
\hline Técnico de informática & 6h/semanais & & 400,00 & 450 & 500 \\
\hline Mediador tecnológico & $4 \mathrm{~h} /$ semanais & 16,00 & 400,00 & 450 & 500 \\
\hline Funcionário da manutenção & 6h/semanais & 12,50 & 300,00 & 400 & 450 \\
\hline Professores & $10 \mathrm{~h} /$ semanais & 16,74 & 670,00 & 770 & 830 \\
\hline Diretor & $10 \mathrm{~h} /$ semanais & 16,74 & 670,00 & 770 & 830 \\
\hline Coordenador Pedagógico & $10 \mathrm{~h} /$ semanais & 16,74 & 670,00 & 770 & 830 \\
\hline Total de contrapartida & $46 \mathrm{~h} /$ semanais & 144,94 & $3.110,00$ & $3.610,00$ & $3.940,00$ \\
\hline
\end{tabular}




\section{Érica Cristina dos S. B. Machado}

\begin{tabular}{|c|c|c|c|c|}
\hline \multicolumn{4}{|c|}{ Cálculo da Necessidade de Recursos } & \multirow[b]{2}{*}{ TOTAL } \\
\hline Item & ANO 1 & ANO 2 & ANO 3 & \\
\hline I. Total das Despesas Correntes & $22.320,00$ & $22.320,00$ & $22.320,00$ & $66.960,00$ \\
\hline Material de Consumo & $6.720,00$ & $6.720,00$ & $6.720,00$ & $20.160,00$ \\
\hline Passagens e Despesas com Locomoção & $2.400,00$ & $2.400,00$ & $2.400,00$ & $7.200,00$ \\
\hline Serviços de Terceiros & $13.200,00$ & $13.200,00$ & $13.200,00$ & $39.600,00$ \\
\hline II. Total de Despesas Administrativas & - & $\cdot$ & - & - \\
\hline III. Total de Despesas com Pessoal & $3.110,00$ & $3.610,00$ & $3.940,00$ & $10.660,00$ \\
\hline IV. Total de Despesas de Capital (investimentos) & $18.500,00$ & $10.000,00$ & $10.000,00$ & $38.500,00$ \\
\hline Necessidade de Recursos (I+II+III+IV) & $43.930,00$ & $35.930,00$ & $36.260,00$ & $116.120,00$ \\
\hline Recursos Edital & $40.820,00$ & $32.320,00$ & $32.320,00$ & $105.460,00$ \\
\hline Recursos da Organização (contrapartida) & $3.110,00$ & $3.610,00$ & $3.940,00$ & $10.660,00$ \\
\hline
\end{tabular}

